\title{
Working Paper: The Impact of COVID-19 Mask Mandates on Consumer Spending
}

\author{
By Prosser Cathey
}

The debate around the effects of the imposition of COVID-19 mask mandates has been fervent, however, little research has been done on the economic effects of these mandates. I find that mask mandates have a positive average treatment effect of $3 \%$ on consumer spending. I then use survey data to confirm the mechanism: people tend to feel more comfortable participating in the economy when mask-wearing is common. Finally, I provide an estimate of the increase in tax revenue state and local governments can expect to receive as a result of implementing a mask mandate, finding a mask mandate can offset a substantial portion of the pandemic-induced decline in tax revenue.

\section{Introduction}

Over the course of the pandemic, health officials and medical experts have consistently identified wide-spread mask wearing as a key mechanism through which we can slow the spread of the virus (Centers for Disease Control and Prevention 2020). This has naturally led governments to ask the question "Should mask-wearing be required?" In attempting to answer this question, much of the public debate has been centered around the trade-off between personal liberties and public health. Some argue that a mask mandate is an unacceptable and unconstitutional encroachment on personal freedoms, while others argue it is a practical and necessary step to save lives. I offer no endorsement of either side of this increasingly partisan divide, but rather seek to shed some light on a part of this debate which has been relatively under-studied and under-discussed: the economic implications of a mask mandate.

I ask the question "How do mask mandates affect consumer spending?" and use the variation from staggered policy implementation to answer it. I use a fixed effects approach estimate mask mandates result in a $3.2 \%$ increase in consumer spending. I then visualize and examine how this effect changes over time via an event study. I find survey data backs up my mechanism hypothesis that people feel more comfortable going out and spending money when mask usage is common place; $88 \%$ of survey respondents indicate that others wearing masks is an important consideration when deciding whether to leave their home. Finally,

Please find the code and data stored here I thank Ro'ee Levy, Jonathan Cohen, Shakked Noy, and Simon Jäger for their helpful feedback. Email: pmcathey@mit.edu. Affiliation: Massachusetts Institute of Technology. Mailing Address: 269 Forbesway Rd. PO Box J, Ligonier, PA, 15658, USA. Phone: (724) 420-0913. Word count : 3,563. 
I use my results to calculate the tax revenue state and local governments can expect to receive from implementing a mask mandate. On average, states with a sales tax can expect a $1.1 \%$ increase in their tax revenue, which correlates to an approximately $\$ 200$ million increase in tax revenue.

My paper contributes to a broader literature on the effects of mask mandates, which almost exclusively focuses on the public health effects. Notable among the studies that focus on the public health implications of a mask mandate is Lyu and Wehby (2020), a similar approach to that which I use. Lyu and Wehby (2020) use an event study design to look at the effects of state-level mask mandates on COVID-19 infection rates. Also of relevance is Hansen (2020), in which Goldman Sachs analysts claim that mask mandates could save the U.S. up to $\$ 1$ trillion due to mask mandates saving lives and improving public health. I distinguish my work from that of Goldman Sachs by focusing on the direct implications of mask mandates on the economy rather than the indirect effect of mask mandates' effect on lives saved, which in turn impacts the economy. To the best of my knowledge, I am the first to directly link COVID-19 mask mandates and economic outcomes.

\section{Background Information and Description of Data}

Mask mandates have become a widely used tool in fighting the spread of COVID-19, but have garnered much debate. Since the consensus among public health experts is that wide spread mask usage reduces COVID-19 transmission, many governments have taken steps to encourage people to wear masks when interacting with others. These steps have ranged from recommendations and advice to strict requirements with penalties for non-compliance. In the United States, many of these mandates have been surrounded by an increasingly partisan debate over the trade-off between public health and personal freedom.

In order to make a causal claim, the variation in timing of mask mandate implementations must exogenous and driven by factors unrelated to economic outcomes; I believe it to be so for three reasons. Firstly, the timing of these mandates varies widely; with state and local governments implementing mask mandates as early as March $16^{\text {th }}$ and as late as August $5^{\text {th }}$. Additionally, mask mandates are not clustered around a certain date. For example, if a high proportion of counties imposed mask mandates on June $1^{\text {st }}$, then it would be reasonable to suggest that something else happened on June $1^{\text {st }}$ which was driving the increase in consumer spending. However, I show in Figures 2 and 3 that the timing of mask mandates is distributed fairly evenly throughout the course of the pandemic. Qualitatively, to the best of my knowledge, there is no outside pressure driving the implementation of mask mandates by state and local governments. Rather, their adoptions seems to be driven by the idiosyncrasies of different governmental procedures and local politics. This is supported by the timing of other public policies, such as stay at home orders or restaurant closings, which similarly seem to be not only uncorrelated with anything in particular but also uncorrelated with each other. Note also that assuming exogeneity is consistent with the literature on COVID-19 
government responses, see Lin and Meissner (2020) for one example.

I acquire the data necessary to perform my analysis from a number of sources. I use the data that Wright et. al (2020) compile on tracking mask mandates by county. It consists of each U.S. county and the mask mandates implemented, whether by state or local governments. In counties which are primarily made up of a city, city-wide ordinances were viewed as applicable to the county. Throughout the paper, I use Opportunity Insight's panel data on consumer spending by county. It reports the seven-day moving average of seasonally adjusted credit/debit card spending relative to January 4-31, 2020, in all merchant category codes from February $1^{\text {st }}$ to August $30^{\text {th }}$. I merge these two data-sets by county and date, leaving a data-set of 354,046 total daily observations for 1,670 counties. This is the data on which I perform my analysis. To add covariates for population and political affiliation, I use data-sets from the United States Department of Agriculture and the MIT Election Lab, respectively. The United States Department of Agriculture codes each county on an urban to rural continuum. MIT Election Data reports the percentage of votes each Presidential candidate received in 2016. I use Killeen et. al (2020) to source state-level data on the reopening of the economy; I find there to be minimal temporal connection between the re-openings and mask mandates. I also use Killeen et. al (2020)'s data which reports the number of new COVID-19 cases per county per day.

To further investigate my proposed mechanism, I conduct a survey. I use Prolific to ask United States residents the question "When deciding whether or not to leave your home for non-essential tasks, how important is it to you that others wear masks?". Respondents indicate their answers on a 1-7 scale. I collect responses from 57 participants.

\section{Empirical Design}

\section{A. Fixed Effects}

To estimate mask mandates' effect on consumer spending, I use a fixed effects approach. This produces an estimate of the average difference in consumer spending between those countries with mask mandates and those without, across all time periods. I limit my analysis to between 50 days before mandate implementation and 125 days after mandate implementation. I choose 125 as the upper bound because beyond this point data quality deteriorates. I choose -50 as the lower bound because this is the point at which consumer spending stabilizes. Before -50 , I see a "v-shape", most likely the result of the onset of the pandemic. While this is the maximum reasonable time-frame given the data, as shown in Section IV, my results also hold for shorter time-frames as well. Appendix D presents the full range of data I have. The stylized version of the regression is

$$
C S_{c, t}=\alpha+\beta \text { Treated }_{c, t}+\text { Cases }_{c, t}+\text { Deaths }_{c, t}+N P I_{c, t}+\gamma_{c}+\epsilon_{c, t}
$$


where $C S$ is consumer spending in a given county at a given time, Treated is a dummy for experiencing a mask mandate, Cases is the number of confirmed cases, Deaths is the number of confirmed deaths, NPI is a vector of dummies for non-pharmaceutical interventions, and $\gamma_{c}$ is a vector of county fixed effects. The non-pharmaceutical interventions I was able to obtain data for were stay at home orders, in-person restaurant bans, gym \& entertainment bans, 50 person gathering bans, and 500 person gathering bans. I include COVID-19 cases and deaths in my regression because they are likely to be causally linked to mask mandates and economic activity. However, as shown in my robustness check in Appendix A, they only slightly affect my estimate. To determine a causal effect, I need the following assumption to hold: the error term must be independent of treatment, conditional on the controls. To put this into words, mask mandates must not have been given to places on differential trends.

\section{B. Event Study}

To visualize the effect of mask mandates on consumer spending and measure how that effect varies relative to the treatment date, I use an event study approach. I use the day before treatment (coded as -1 ) as the reference date and again limit the time period to between 50 days before mandate implementation and 125 days after mandate implementation. I run the regression

$$
C S_{c, t}=\alpha+\sum_{t \neq-1} \delta_{t} \times \text { Day }_{t}+\text { Cases }_{c, t}+\text { Deaths }_{c, t}+N P I_{c, t}+\gamma_{c}+\epsilon_{c, t}
$$

where, as before, $C S$ is consumer spending in a given county at a given time, Cases is the number of confirmed cases, Deaths is the number of confirmed deaths, NPI is a vector of dummies for non-pharmaceutical interventions, and $\gamma_{c}$ is a vector of county fixed effects. As above, the non-pharmaceutical interventions I include were stay at home orders, in-person restaurant bans, gym \& entertainment bans, 50 person gathering bans, and 500 person gathering bans. The main coefficients of interest are $\delta_{t}$.

\section{Results}

\section{A. Main Results}

Using a fixed effects approach, I find mask mandates increase consumer spending by $3.2 \%$. The effect is precise, with standard errors clustered at the county level being $.2 \%$. I present the regression table, along with robustness checks, in Table A. For scale, so far this year consumer spending has been down $8.8 \%$ compared to pre-pandemic levels, on average. This indicates that in pandemic conditions, local mask mandates tend to result in substantial increases in consumer spending. 
I plot the estimated coefficients $\hat{\delta}_{t}$ from my event study in Figure 1 to capture how consumer spending jumps after mask mandate implementation. The pre-treatment period shows no clear trend, appearing to be generally constant. Immediately upon treatment, there is a noticeable trend: for the first approximately 65 days post treatment the estimates consistently increase. At treatment, there is also a significant jump in the estimate. The estimates are statistically significantly different from the reference date (day -1) at the $90 \%$ level starting at day 1 , the $95 \%$ level starting at day 2 , and the $99.9 \%$ level starting at day 3. The slight lag is likely affected by the fact that my dependent variable, consumer spending is a seven-day moving average. After the initial upwards trend immediately post treatment, consumer spending stabilizes, maintaining its significance and increasing only slightly through the duration of the post-treatment time period.

\section{B. Potential Threats}

I now examine various potential threats to causality. I find no evidence that there exists a variable which varies along with mask mandates and increases consumer spending. The primary candidate would be other policy interventions induced by COVID-19, such as re-openings of gyms and restaurants or the ending of stay at home orders. As Table A shows, controlling for non-pharmaceutical interventions does decrease the magnitude of my estimate, but my estimate maintains its statistical significance. In Appendix E, I present the distribution of the timing of policies concerning 50-person gatherings, 500-person gatherings, restaurants, gyms and stay at home orders, relative to mask mandate implementation dates. I find little temporal correlation between mask mandates and non-pharmaceutical interventions. I formally test the effect of all non-mask mandate NPIs in an event study presented in Figure E6. When looking at a dummy variable for the existence of any non-mask mandate NPI, there is no statistically significant change correlating with the implementation of mask mandates. I also include the number of COVID-19 cases and deaths as covariates in Regression 1 since mask mandates have the potential to be correlated with cases and deaths, both of which likely decrease consumer spending. As shown in Table A, I found that including cases and deaths in my analysis results in a slightly higher and roughly equally precise estimate for the coefficient of interest.

I explore the possibility that pre-treatment trends indicate there would have been an increase in consumer spending. Figure D1 shows median consumer spending is roughly constant for a period of 50 days prior to the treatment date. Additionally, after 50 days of roughly constant consumer spending, there is a significant, permanent increase just three days after treatment despite the fact that consumer spending is measured via a seven day moving average. Therefore I do not consider pre-treatment trends to indicate that consumer spending would have increased as much as the observed increase.

Though mandate implementation primarily occurs at the local level, a non- 
negligible amount of mask mandates come from state government. To account for this, I rerun my regressions, clustering my standard errors at the state level. The results are approximately the same.

Thus far, I have performed analysis on the maximum reasonable timeline given the data, however, if mask mandates really do have a causal effect on consumer spending then then ideally the effect is significant for shorter time-frames as well. I repeat my analysis, running Regression 1 again on the subset of data within 31 days of the mandate and within 7 days of the mandate. Both regressions produce significant results: $2.3 \%$ with standard errors of $0.002 \%$ and $1.6 \%$ with standard errors of $0.002 \%$, respectively.

I perform robustness checks, re-running Regression 1 with various covariates. The results are presented in Table A. Consistent with my causal claim, mask mandates have a significant effect in all regressions run. Also of note, adding covariates for the effect of non-pharmaceutical interventions (stay at home orders, bans on 50 person gatherings, et cetera) did decrease the value of my estimate, but not enough to threaten my claim of causality.

Due to the elimination of the above potential threats to causality, I provisionally consider the results of my analysis to carry causal implications.

\section{Mechanism}

I view the most likely mechanism by which mask mandates affect consumer spending as the following: mask mandates result in more people wearing masks; more people wearing masks results in people feeling safer leaving their home; and people feeling safer leaving their house results in them spending more money. I conduct a survey via Prolific, with a sample size of 50 taken from United States residents. I find my survey data is consistent with this mechanism; $72 \%$ of respondents indicate that others' mask wearing was a very important indicator in deciding whether to leave their home. Furthermore, $87.7 \%$ respond in the 5-7 range, where responses were given on a 7 point scale where 1 is "not important at all" and 7 is "very important."

At first my proposed mechanism seems to imply there should only be a discrete jump around the treatment cutoff, not necessarily a change in slope. However, a change in slope is, in fact, consistent with many individuals experiencing a delayed version of my mechanism. For example, if it was necessary for someone to see for themselves that mask wearing is now frequent, then whenever they see this is when they would spend their money, as opposed to immediately posttreatment. Alternatively, suppose that, in order to venture out, another person needs the assurance of a family member who can verify that mask wearing is high and shopping is safe. Then they would not only have to wait until that family member was sufficiently convinced but also until they had the chance to discuss the situation with them. In these ways, a feeling of slightly increased safety due to the heightened level of mask wearing that mask mandates induce could spread through the population in the days and weeks immediately after implementation. 


\section{Heterogeneity}

I find slight evidence that treatment effects are heterogeneous over time. I divide the data in half, using the middle date for my data: (May $16^{\text {th }}$ ). I rerun Regression 1 for both the first half and second half. As shown in Table C1, both time periods produce statistically significant estimates for the effect of mask mandates on consumer spending. Note, however, that the magnitude varies by time period; I estimate a $5.0 \%$ (.006) increase in consumer spending for the first half and a $2.3 \%$ (.002) increase for the second half. I theorize that, as the pandemic progressed, mask wearing became more common even in areas without a mandate and businesses became more likely to implement their own requirements. As such, the effect of a mandate on mask wearing decreases as time went on.

I now examine heterogeneity over groups. I first examine population density, as the effect of a mask mandate could be different in cities than in rural areas since frequent close contact with other people could result in greater desire to wear a mask. I use the urban-rural codes developed by the U.S. Department of Agriculture that score each county on a scale of 1 to 9 , with 1 being the most urban and 9 being the most rural. As shown in TableC2, mask mandates maintain their statistically significant effect on consumer spending in all population densities. Additionally, the interaction term is negative and statistically significant at the $95 \%$ level, suggesting that mask mandates have a larger effect on consumer spending in urban areas than rural ones. This is consistent with my proposed mechanism; people who regularly come in close contact with others would care more about others wearing a mask than a person who rarely comes into close contact with others.

I also examine heterogeneity across political affiliation, as measured by Democratic vote share in the 2016 election. As with population density, mask mandates appear to maintain their significant effect on consumer spending across all vote shares. Additionally, the interaction term is significant at the $99 \%$ level, indicating that mask mandates have a larger effect on consumer spending in more Democratic counties. An explanation for this that is consistent with my proposed mechanism is that those who identify as Republican may be more likely to ignore government mandates. This would result in less people wearing masks, making people less comfortable leaving their homes and spending money.

Finally, I examine heterogeneity across COVID-19 intensity, presenting my results in Table C2. I use COVID-19 deaths as a proxy for the intensity of the pandemic, though using cases gives roughly the same results. I find that the interaction term is not statistically significant, indicating that the effect of mask mandates on consumer spending does not vary with the intensity of the pandemic. This contradicts my proposed mechanism, since the mechanism would predict that the effect of mask mandates on consumer spending is more salient in areas where the pandemic is more intense. More research needs to be done into my proposed mechanism to reconcile this apparent contradiction. 


\section{E. Implications}

I now focus on the policy applications of my findings. Since an increase in consumer spending is not perfectly correlated with state sales tax revenue, my calculations should be viewed as upper bounds rather than point estimates. While my analysis was done on the county level since that was where treatment time varied, I present policy implications at the state level because that is the level of government which most commonly taxes consumer spending directly. Since the average state receives $23.1 \%$ of their tax revenue from consumer spending, a $3.1 \%$ increase in consumer spending could produce a substantial increase in a state's overall tax revenue (Federation of Tax Administrators). The sources of states' tax revenue vary significantly, so the expected amount gained as a result of a mask mandate is presented on a per state basis in Table B1. Averaging across states that have a sales tax, mask mandates can be expected to increase state tax revenue by $1.1 \%$. The maximum expected increase is in Florida at $2.06 \%$, while the lowest expected increase is in the few states that don't have a sales tax. Using the same approach gives an estimate for an average absolute increase in revenue of $\$ 202,518,629$.

\section{Conclusion}

In summary, I use a fixed effects approach at the United States county level to find the average treatment effect of a mask mandate on consumer spending. I complement this by using an event study approach to visualize and measure how the effect varies over time. I use survey data to confirm the mechanism that people do, in fact, tend to feel more comfortable participating in the economy when mask-wearing is common. I provisionally assume causality given the analysis currently conducted. Based on my results, I conclude that governments in areas where people are concerned about catching COVID-19 can expect to see an uptick in consumer spending of on average $3.2 \%$, if they implement a mask mandate. Likewise, states with a sales tax can expect to see a $1.1 \%$ increase in tax revenue, on average, which corresponds to an approximately $\$ 200$ million absolute increase.

\section{References}

[1] United States Department of Agriculture. Rural-Urban Continuum Codes. URL: https://www.ers.usda.gov/data-products/rural-urban-continuumcodes.aspx. (accessed: 09.30.2020).

[2] Tax Policy Center. What are the sources of revenue for state governments? URL: https://www.taxpolicycenter.org/briefing-book/what-are-sourcesrevenue- state- governments $\#: \sim$ : text $=$ State $\% 5 \mathrm{C} \%$ 20government $\% 5 \mathrm{C} \%$ 20revenue $\%$ 5C \% 20comes \% 5C \% 20from, transfers \% 5C \% 20from \% 5C \% 20the\%5C\%20federal\%5C\%20government.\&text=General\%5C\%20revenue $\%$ 
5C\%20from $\% 5 \mathrm{C} \% 20$ income $\% 5 \mathrm{C} \% 2 \mathrm{C} \% 5 \mathrm{C} \% 20$ sales, general $\% 5 \mathrm{C} \% 20$ revenue $\%$ 5C\%20(figure\%5C\%201).. (accessed: 09.30.2020).

[3] Sergio Correia, Stephan Luck, and Emil Verner. "Pandemics Depress the Economy, Public Health Interventions Do Not: Evidence from the 1918 Flu". In: Working Paper (2020).

[4] MIT Election Data and Science Lab. County Presidential Election Returns 2000-2016. Version V6. 2018. DOI: 10.7910/DVN/VOQCHQ. URL: https: //doi.org/10.7910/DVN/VOQCHQ.

[5] Centers for Disease Control and Prevention. CDC calls on Americans to wear masks to prevent COVID-19 spread. URL: https://www.cdc.gov/ media / releases / 2020 / p0714 - americans - to- wear - masks . html. (accessed: 09.30.2020).

[6] Sarah Hansen. "A National Mask Mandate Could Save The U.S. Economy $\$ 1$ Trillion, Goldman Sachs Says". In: Forbes (2020), p. 1.

[7] Benjamin D. Killeen et al. "A County-Level Dataset for Informing the United States' Response to COVID-19”. In: (Apr. 2020). arXiv: 1909.11730.

[8] Zhixian Lin and Christopher M. Meissner. "Health vs. Wealth? Public Health Policies and the Economy During Covid-19". In: Working Paper (2020).

[9] Wei Lyu and George L. Wehby. "Community Use Of Face Masks And COVID-19: Evidence From A Natural Experiment Of State Mandates In The US". In: Health Affairs 39.8 (2020). DoI: https://doi.org/10.1377/ hlthaff.2020.00818.

[10] Affinity Solutions via Opportunity Insights. Economic Tracker. URL: https: //github.com/OpportunityInsights / EconomicTracker / blob/main/data/ Affinity\%20-\%20County\%20-\%20Daily.csv. (accessed: 09.30.2020).

[11] Federation of Tax Administrators. Multiple Pages. URL: https://www. taxadmin.org/. (accessed: 09.30.2020).

[12] Austin L. Wright et al. "Tracking Mask Mandates during the COVID-19 Pandemic". In: Working Paper 104 (2020). 


\section{Mask Mandate and Consumer Spending: Event Study}

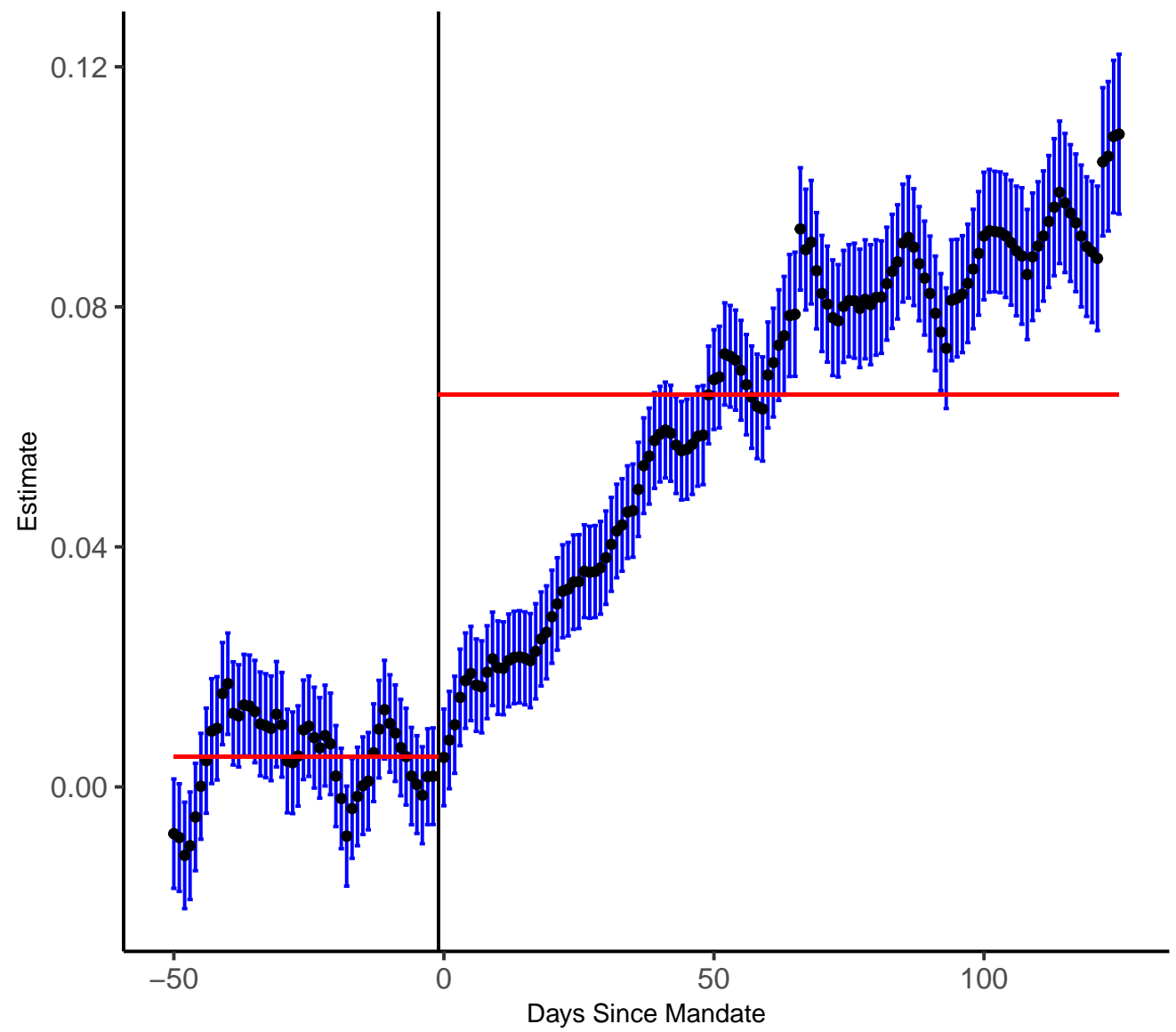

Figure 1. This figure presents event study coefficients from Equation 2 Showing the effects OF MASK MANDATES ON CONSUMER SPENDING OVER TIME. I USE THE DAY BEFORE TREATMENT (CODED AS -1) AS THE REFERENCE DATE AND AGAIN LIMIT THE TIME PERIOD TO BETWEEN 50 DAYS BEFORE MANDATE IMPLEMENTATION AND 125 DAYS AFter MANDATE implementation. Note the ABSOlute inCREASE AND

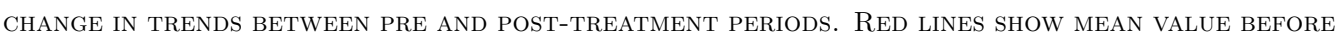
and after mask mandate implementation. Error bars show 95\% COnfidence intervals. The ESTIMATES ARE STATISTICALlY SIGNIFICANTLY DifFERENT FROM THE REFERENCE DATE (DAY -1) AT THE

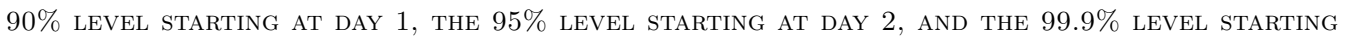
AT DAY 3. 


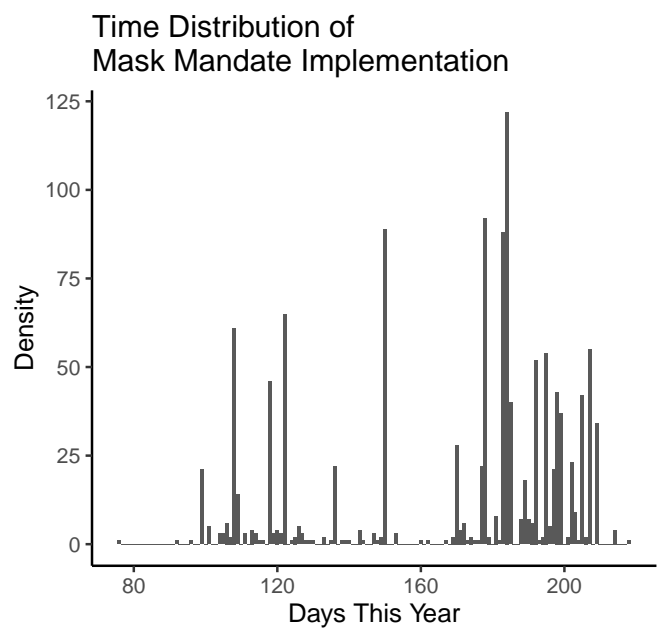

Figure 2. Note that the timing OF MASK MANDATE IMPLEMENTATION IS VARIED AND FAIRLY EVENLY

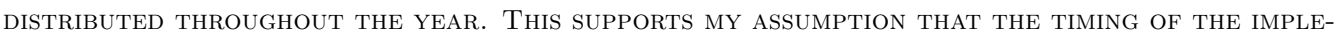
MENTATION OF MASK MANDATES IS EXOGENOUS. ASSUMing EXOGENEITY IS NECESSARY FOR My CAUSAL CLAIM THAT MASK MANDATES INCREASE CONSUMER SPENDING.

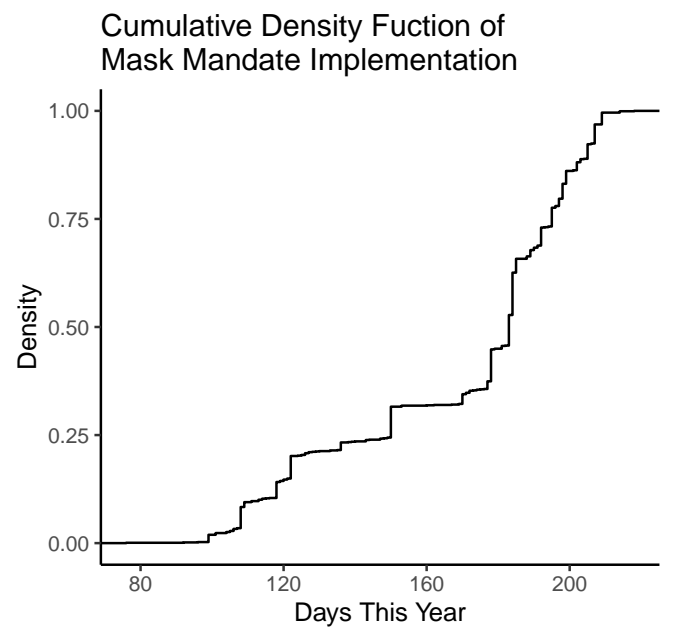

Figure 3. Note that the timing OF MASk MANDATE IMPLEMENTATION IS VARIED AND FAIRLY EVENLY Distributed throughout the YeAR. THIS SUPPORTS MY ASSUMPtion that THE TIMING OF THE IMPLEMENTATION OF MASK MANDATES IS EXOGENOUS. ASSUMing EXOGENEITY IS NECESSARY FOR My CAUSAL CLAIM THAT MASK MANDATES INCREASE CONSUMER SPENDING. 


\section{Appendix A - Robustness Checks}

\begin{tabular}{|c|c|c|c|c|}
\hline & \multicolumn{4}{|c|}{ Dependent variable: } \\
\hline & \multicolumn{4}{|c|}{ Consumer Spending } \\
\hline & No Controls & County Fixed Effects & Cases and Deaths & NPIs \\
\hline Mask Mandate & $\begin{array}{c}0.047^{* * *} \\
(0.003)\end{array}$ & $\begin{array}{c}0.063^{* * *} \\
(0.002)\end{array}$ & $\begin{array}{c}0.069^{* * *} \\
(0.002)\end{array}$ & $\begin{array}{c}0.032^{* * *} \\
(0.002)\end{array}$ \\
\hline COVID-19 Cases & & & $\begin{array}{c}-0.00000^{* *} \\
(0.00000)\end{array}$ & $\begin{array}{c}-0.00000^{*} \\
(0.00000)\end{array}$ \\
\hline COVID-19 Deaths & & & $\begin{array}{l}0.0001^{* * *} \\
(0.00002)\end{array}$ & $\begin{array}{c}0.00004^{* * *} \\
(0.00001)\end{array}$ \\
\hline Stay at Home Order & & & & $\begin{array}{c}-0.057^{* * *} \\
(0.003)\end{array}$ \\
\hline Restaurant Closings & & & & $\begin{array}{c}-0.057^{* * *} \\
(0.007)\end{array}$ \\
\hline Gym Closings & & & & $\begin{array}{l}-0.009 \\
(0.007)\end{array}$ \\
\hline $\begin{array}{l}50 \text { Person } \\
\text { Gatherings Ban }\end{array}$ & & & & $\begin{array}{l}-0.002 \\
(0.008)\end{array}$ \\
\hline $\begin{array}{l}500 \text { Person } \\
\text { Gatherings Ban }\end{array}$ & & & & $\begin{array}{l}-0.009 \\
(0.009)\end{array}$ \\
\hline $\begin{array}{l}\text { Federal Guidelines } \\
\text { Followed }\end{array}$ & & & & $\begin{array}{c}-0.155^{* * *} \\
(0.009)\end{array}$ \\
\hline Foreign Travel Ban & & & & $\begin{array}{c}-0.033^{* * *} \\
(0.011)\end{array}$ \\
\hline Observations & 153,798 & 153,798 & 148,233 & 148,233 \\
\hline & 0.026 & 0.582 & $\begin{array}{l}0.619 \\
0.20\end{array}$ & $\begin{array}{l}0.673 \\
0.200\end{array}$ \\
\hline Adjusted $R^{2}$ & 0.026 & 0.578 & 0.616 & 0.670 \\
\hline Residual Std. Error & $0.142(\mathrm{df}=153796)$ & $0.093(\mathrm{df}=152552)$ & $0.089(\mathrm{df}=146990)$ & $0.082(\mathrm{df}=146983)$ \\
\hline
\end{tabular}

Notes: Here I run robustness checks for Regression 1 While it decreases with the addition of NPIs, my estimate for the effect of mask mandates on consumer spending remains statistically significant and positive across all columns. This supports my claim of causality.

Appendix B - Expected Revenue Increase by State from a Mask Mandate

Table B1-: Percentage Change in Tax Revenue

\begin{tabular}{cc}
\hline \hline State & Percentage Change \\
\hline Alabama & $0.81 \%$ \\
Arizona & $1.51 \%$ \\
Arkansas & $1.14 \%$ \\
California & $0.66 \%$ \\
Colorado & $0.70 \%$ \\
Connecticut & $0.76 \%$ \\
DC & $0.60 \%$ \\
Florida & $2.06 \%$
\end{tabular}




\begin{tabular}{cl} 
Georgia & $0.81 \%$ \\
Hawaii & $1.47 \%$ \\
Idaho & $1.18 \%$ \\
Illinois & $0.91 \%$ \\
Indiana & $1.39 \%$ \\
Iowa & $0.94 \%$ \\
Kansas & $1.21 \%$ \\
Kentucky & $0.96 \%$ \\
Louisiana & $1.20 \%$ \\
Maine & $1.21 \%$ \\
Maryland & $0.57 \%$ \\
Massachusetts & $0.60 \%$ \\
Michigan & $1.14 \%$ \\
Minnesota & $0.70 \%$ \\
Mississippi & $1.45 \%$ \\
Missouri & $1.01 \%$ \\
Nebraska & $1.13 \%$ \\
Nevada & $1.78 \%$ \\
New Jersey & $0.91 \%$ \\
New Mexico & $1.17 \%$ \\
New York & $0.54 \%$ \\
North Carolina & $1.02 \%$ \\
North Dakota & $0.70 \%$ \\
Ohio & $1.34 \%$ \\
Oklahoma & $0.91 \%$ \\
Pennsylvania & $0.76 \%$ \\
Rhode Island & $1.07 \%$ \\
South Carolina & $1.00 \%$ \\
South Dakota & $1.85 \%$ \\
Tennessee & $1.58 \%$ \\
Texas & $1.92 \%$ \\
Utah & $1.00 \%$ \\
Vermont & $0.39 \%$ \\
Virginia & $0.66 \%$ \\
Washington & $1.89 \%$ \\
West Virginia & $0.68 \%$ \\
Wisconsin & $1.14 \%$ \\
Wyoming & $1.10 \%$ \\
\hline &
\end{tabular}

Notes: Here I calculate the average percent increase in tax revenue each state could expect from implementing a mask mandate. This is obtained by using my estimate for the average effect of mask mandates on consumer spending and assuming that consumer spending directly correlates to an increase in sales tax revenue. I have excluded states without a sales tax. The variance in percent increases reflects the variance in state tax revenue sources. 


\section{Appendix CP Exploring Heterogeneity across Time and Groups}

Table C1-Heterogeneous Effects across Time

\begin{tabular}{|c|c|c|}
\hline & \multicolumn{2}{|c|}{ Consumer Spending } \\
\hline & (First Half) & (Second Half) \\
\hline Mask Mandates & $\begin{array}{c}0.050^{* * *} \\
(0.006)\end{array}$ & $\begin{array}{c}0.023^{* * *} \\
(0.002)\end{array}$ \\
\hline COVID-19 Cases & $\begin{array}{c}-0.00002^{* * *} \\
(0.00000)\end{array}$ & $\begin{array}{c}0.00000 \\
(0.00000)\end{array}$ \\
\hline COVID-19 Deaths & $\begin{array}{c}0.0002^{* * *} \\
(0.0001)\end{array}$ & $\begin{array}{c}0.0001^{* * *} \\
(0.00002)\end{array}$ \\
\hline Stay at Home Order & $\begin{array}{l}-0.103^{* * *} \\
(0.006)\end{array}$ & $\begin{array}{l}-0.026^{* * *} \\
(0.003)\end{array}$ \\
\hline Restaurant Closings & $\begin{array}{c}-0.053^{* *} \\
(0.021)\end{array}$ & $\begin{aligned}-0.022^{* * *} & (0.008)\end{aligned}$ \\
\hline Gym Closings & $\begin{array}{c}0.027 \\
(0.021)\end{array}$ & $\begin{array}{c}0.006 \\
(0.008)\end{array}$ \\
\hline $\begin{array}{l}50 \text { Person } \\
\text { Gathering Ban }\end{array}$ & $\begin{array}{c}0.002 \\
(0.021)\end{array}$ & $\begin{array}{c}-0.034^{* *} \\
(0.013)\end{array}$ \\
\hline $\begin{array}{l}500 \text { Person } \\
\text { Gathering Ban }\end{array}$ & $\begin{array}{c}-0.096^{* * *} \\
(0.023)\end{array}$ & $\begin{array}{c}0.017 \\
(0.014)\end{array}$ \\
\hline $\begin{array}{l}\text { Federal Guidelines } \\
\text { Followed }\end{array}$ & $\begin{array}{l}-0.190^{* * *} \\
(0.009)\end{array}$ & $(0.000)$ \\
\hline Foreign Travel Ban & $\begin{array}{l}-0.014 \\
(0.011) \\
\end{array}$ & $(0.000)$ \\
\hline Observations & 23,495 & 124,738 \\
\hline $\mathrm{R}^{2}$ & 0.657 & 0.668 \\
\hline Adjusted $\mathrm{R}^{2}$ & 0.645 & 0.665 \\
\hline Residual Std. Error & $0.085(\mathrm{df}=22678)$ & $0.075(\mathrm{df}=123490)$ \\
\hline
\end{tabular}

Notes: Here I explore how the effect of mask mandates on consumer spending has changed with time. I rerun Regression 1 for the first half and second half of my data. I used the middle date of my data, May $16^{\text {th }}$ as the cutoff date. My estimate for the effect of mask mandates on consumer spending remains statistically significantly positive in both halves, but decreases in magnitude in the second half. This is consistent with my proposed mechanism; as the pandemic has gone on mask-wearing has become more common regardless of the implementation of mandates. 
TABle C2 - Heterogeneous EFFeCts By population AND political afFiliation

\begin{tabular}{|c|c|c|c|}
\hline \multirow[b]{3}{*}{ Mask Mandate } & \multicolumn{3}{|c|}{ Dependent variable: } \\
\hline & \multicolumn{3}{|c|}{ Consumer Spending } \\
\hline & $\begin{array}{c}0.040^{* * *} \\
(0.004)\end{array}$ & $\begin{array}{l}0.010^{* *} \\
(0.005)\end{array}$ & $\begin{array}{c}0.032^{* * *} \\
(0.002)\end{array}$ \\
\hline PostDummy_x_ruralurban & $\begin{array}{c}-0.002^{* *} \\
(0.001)\end{array}$ & & \\
\hline Mask Mandate $*$ Democratic Vote Share & & $\begin{array}{c}0.062^{* * *} \\
(0.012)\end{array}$ & \\
\hline Mask Mandate * COVID-19 Deaths & & & $\begin{array}{l}-0.00001 \\
(0.00001)\end{array}$ \\
\hline Cases & $\begin{array}{c}-0.00000^{* *} \\
(0.00000)\end{array}$ & $\begin{array}{c}-0.00000^{* *} \\
(0.00000)\end{array}$ & $\begin{array}{l}-0.00000 \\
(0.00000)\end{array}$ \\
\hline Deaths & $\begin{array}{c}0.00004^{* * *} \\
(0.00001)\end{array}$ & $\begin{array}{c}0.00004^{* * *} \\
(0.00001)\end{array}$ & $\begin{array}{l}0.0001^{* * *} \\
(0.00002)\end{array}$ \\
\hline Stay at Home Order & $\begin{array}{c}-0.057^{* * *} \\
(0.003)\end{array}$ & $\begin{array}{c}-0.057^{* * *} \\
(0.003)\end{array}$ & $\begin{array}{c}-0.057^{* * *} \\
(0.003)\end{array}$ \\
\hline Restaurant Closings & $\begin{array}{l}-0.057^{* * *} \\
(0.007)\end{array}$ & $\begin{array}{l}-0.054^{* * *} \\
(0.007)\end{array}$ & $\begin{array}{c}-0.057^{* * *} \\
(0.007)\end{array}$ \\
\hline Gym Closings & $\begin{array}{l}-0.009 \\
(0.007)\end{array}$ & $\begin{array}{l}-0.009 \\
(0.007)\end{array}$ & $\begin{array}{l}-0.009 \\
(0.007)\end{array}$ \\
\hline $\begin{array}{l}50 \text { Person } \\
\text { Gathering Ban }\end{array}$ & $\begin{array}{l}-0.002 \\
(0.009)\end{array}$ & $\begin{array}{l}-0.001 \\
(0.008)\end{array}$ & $\begin{array}{l}-0.002 \\
(0.008)\end{array}$ \\
\hline $\begin{array}{l}500 \text { Person } \\
\text { Gathering Ban }\end{array}$ & $\begin{array}{l}-0.008 \\
(0.009)\end{array}$ & $\begin{array}{l}-0.011 \\
(0.009)\end{array}$ & $\begin{array}{l}-0.009 \\
(0.009)\end{array}$ \\
\hline $\begin{array}{l}\text { Federal Guidelines } \\
\text { Followed }\end{array}$ & $\begin{array}{c}-0.158^{* * *} \\
(0.009)\end{array}$ & $\begin{array}{c}-0.165^{* * *} \\
(0.010)\end{array}$ & $\begin{array}{c}-0.156^{* * *} \\
(0.009)\end{array}$ \\
\hline Foreign Travel Ban & $\begin{array}{c}-0.033^{* * *} \\
(0.011)\end{array}$ & $\begin{array}{c}-0.035^{* * *} \\
(0.011)\end{array}$ & $\begin{array}{c}-0.033^{* * *} \\
(0.011)\end{array}$ \\
\hline Observations & 148,233 & 148,233 & 148,233 \\
\hline $\mathrm{R}^{2}$ & 0.673 & 0.674 & 0.673 \\
\hline Adjusted $\mathrm{R}^{2}$ & 0.671 & 0.671 & 0.670 \\
\hline Residual Std. Error $(\mathrm{df}=146982)$ & 0.082 & 0.082 & 0.082 \\
\hline
\end{tabular}

Notes: Here I explore how the effect of mask mandates on consumer spending changes with population and political affiliation. I rerun Regression including interaction terms for population density and Democratic vote share. My estimate for the effect of mask mandates on consumer spending remains significant across all levels of population density and political affiliation. I find mask mandates have a statistically significantly larger effect on consumer spending in urban areas than rural ones. This is consistent with my proposed mechanism; people who regularly come in close contact with others would care more about others wearing a mask than a person who rarely comes into close contact with others. My results also indicate that mask mandates have a significantly larger effect on consumer spending in counties that are more Democratic. An explanation for this that is consistent with my proposed mechanism is that those who identify as Republican may be more likely to ignore government mandates. This would result in less people wearing masks, making people less comfortable leaving their homes and spending money. 


\section{Median Consumer Spending and Mask Mandate Implementation Dates}

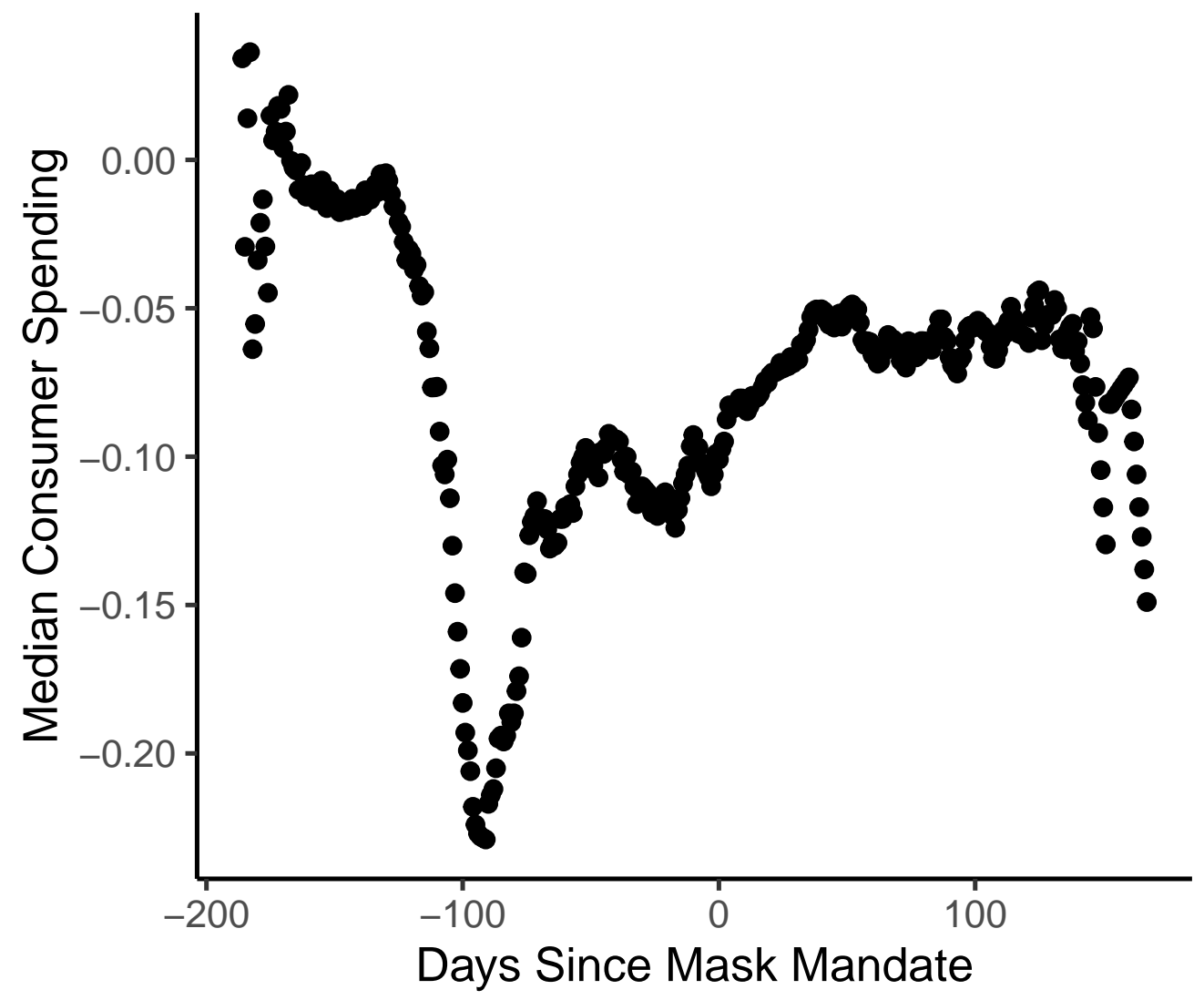

Figure D1. This figure presents the full extent of DAta on CONSUMER SPEnding COMPARED to

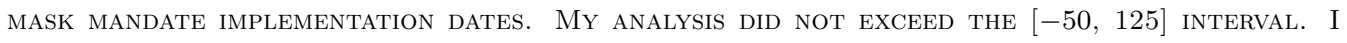
LIMITED MY ANALYSIS TO AFTER DAY -50 BECAUSE THIS IS APPROXIMATELY THE DAY AT WHICH THE VSHAPED TREND IN CONSUMER SPENDING ENDS. I LIMITED MY ANALYSIS TO BEFORE DAY 125 BECAUSE DATA QUALITY APPEARS TO DETERIORATE AT THIS POINT. 


\section{Appendix E- CheCKing For the EXISTEnCe of CONFOUnding VARIABles}

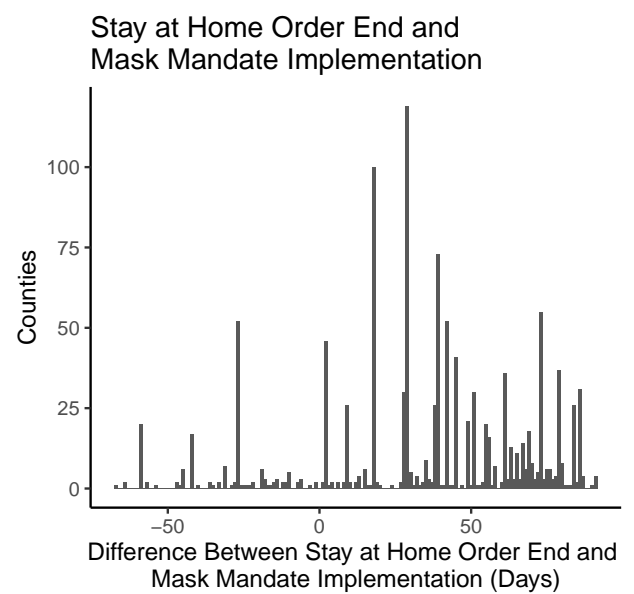

Figure E1. Note that there seems to Be no Correlation Between the lifting of Stay at home ORDERS AND MASK MANDATE IMPLEMENTATION. IF THERE WERE, THERE WOULD BE CLUSTERING NEAR

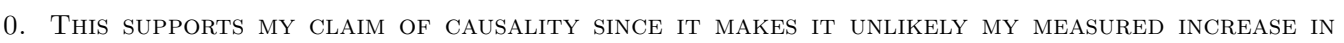
CONSUMER SPENDING CAN BE ATTRIBUTED TO THE ENDING OF STAY AT HOME ORDERS.

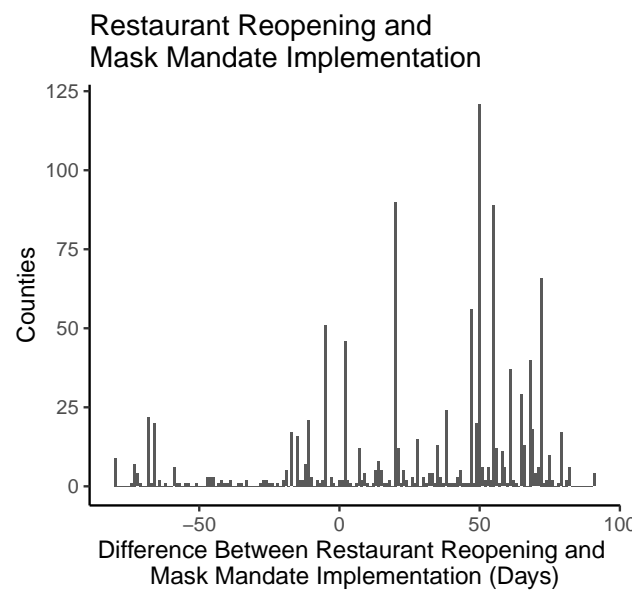

Figure E2. Note that there SEems to be no Correlation Between Restaurant Re-opening Dates AND MASK MANDATE IMPLEMENTATION DATES. IF THERE WERE, THERE WOULD BE ClUSTERING NEAR

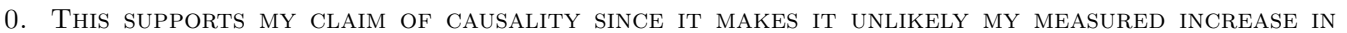
CONSUMER SPENDING CAN BE ATTRIBUTED TO RESTAURANT RE-OPENINGS. 


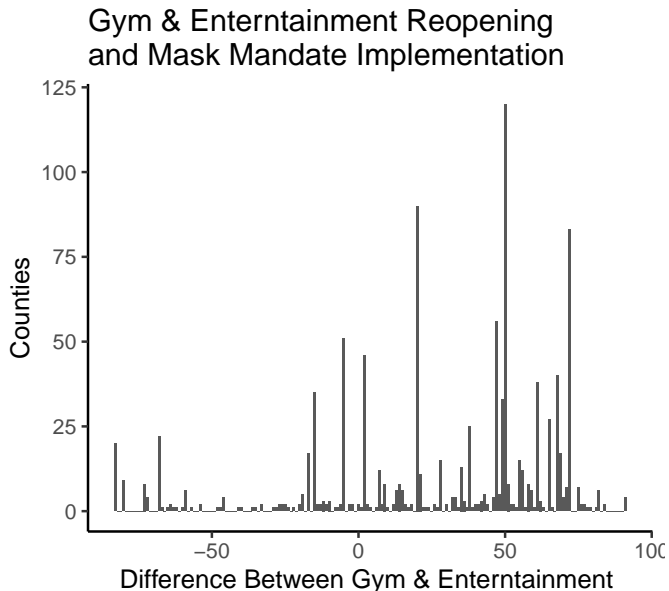

Reopening and Mask Mandate Implementation (Days

Figure E3. Note that there SeEms to Be no CORRELATion BETWEen Gym Re-Openings and mask MANDATE IMPLEMENTATION DATES. IF THERE WERE, THERE WOULD BE CluSTERING NEAR 0. This SUPPORTS MY CLAIM OF CAUSALITY SINCE IT MAKES IT UNLIKELY MY MEASURED INCREASE IN CONSUMER SPENDING CAN BE ATTRIBUTED TO GYM RE-OPENINGS.

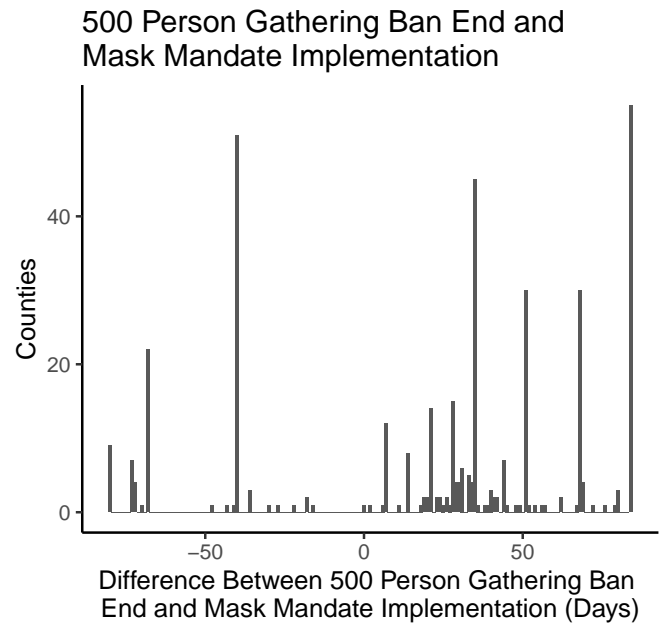

Figure E4. Note that there Seems to Be no Correlation Between the Lifting of 500-Person GATHERING BANS AND MASK MANDATE IMPLEMENTATION DATES. If THERE WERE, THERE WOUld Be ClusTERING NEAR 0. THIS SUPPORTS MY CLAIM OF CAUSALITY SINCE IT MAKES IT UNLIKELY MY MEASURED INCREASE IN CONSUMER SPENDING CAN BE ATTRIBUtED TO THE ENDING OF 500-PERSON GATHERINGS. 
50 Person Gathering Ban End and Mask Mandate Implementation

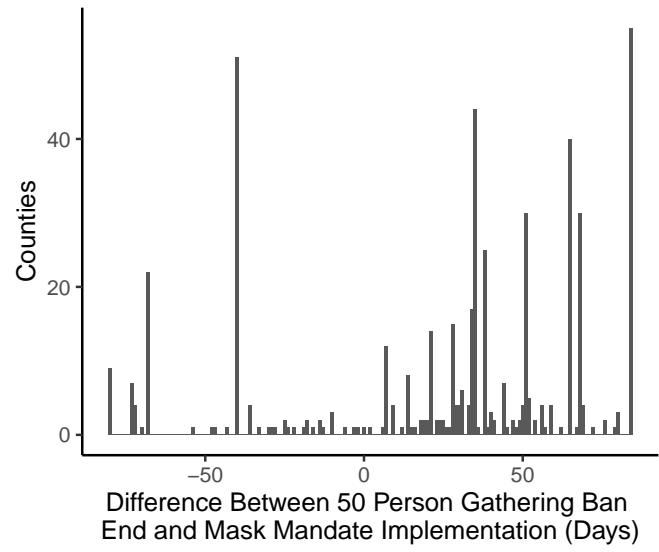

Figure E5. Note that there SeEms to Be no CORrelation Between the Lifting of 50-Person GATHERING BANS AND MASK MANDATE IMPLEMENTATION DATES. IF THERE WERE, THERE WOULD BE Clus-

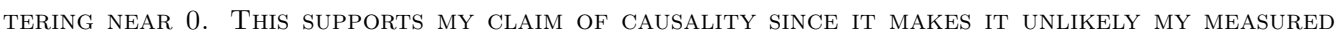
INCREASE IN CONSUMER SPENDING CAN BE ATTRIBUTED TO THE ENDING OF 50-PERSON GATHERINGS.

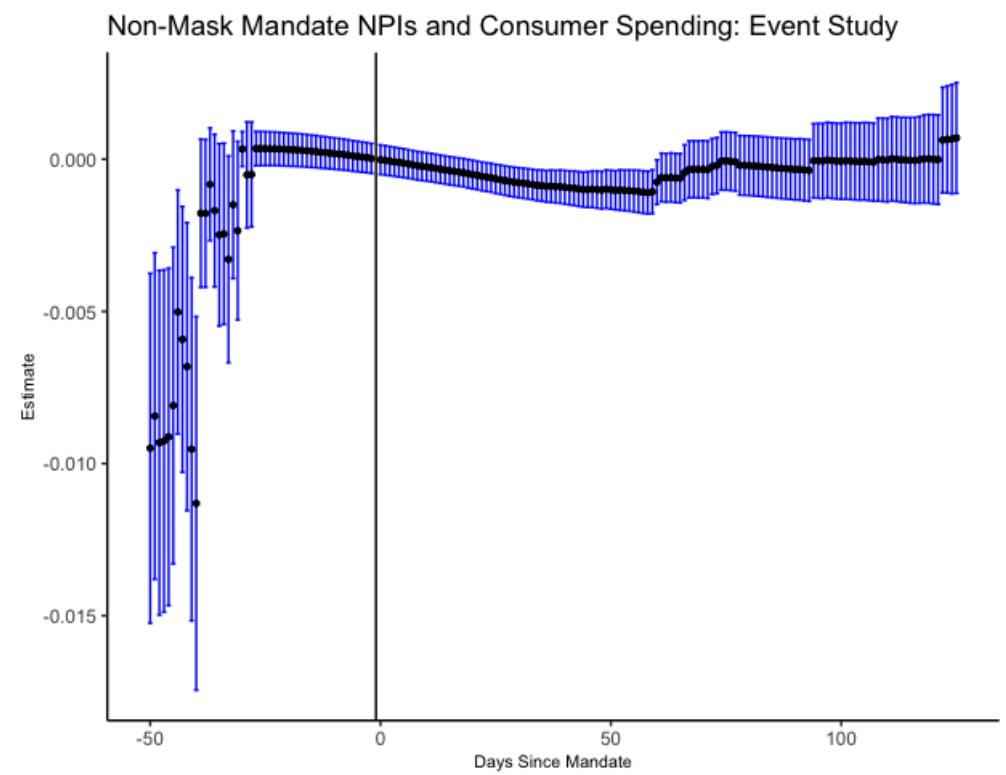

Figure E6. This figure presents an EVEnt Study For a DUMmy VARiable For the EXistence of ANY NON-MASK MANDATE NPI. Note thAT THERE SEEMS TO BE NO DIFFERENCE IN THE PERIOdS BEFORE MASK MANDATE IMPLEMENTATION AND AFTER MASK MANDATE IMPLEMENTATION IN EITHER THE TREND OR ABSOLUTE VALUE OF THE DUMMY VARIABLE. 